\title{
Online Hate: From the Far-Right to the 'Alt-Right', and from the Margins to the Mainstream
} Aaron Winter (UEL)

DRAFT. For citation: Winter, Aaron. 2019. 'Online Hate: From the Far-Right to the 'Alt-Right', and from the Margins to the Mainstream'. Online Othering: Exploring violence and discrimination on the web. eds. Karen Lumsden and Emily Harmer. London: Palgrave.

\begin{abstract}
In the 1990s and early 2000s, there was much discussion about the democratic and anti-democratic implications of the internet, the latter particularly focused on the far-right using it to spread hate and recruit. Despite this, the American far-right did not harness it quickly, effectively or widely. More recently though, they have experienced a resurgence and mainstreaming, benefitting greatly from social media. This chapter will examine the history of the American far-right's use of the internet in light of this, in respect to: 1. How this history developed in response to political changes and emerging technologies; 2 . How it reflected and changed the status of such movements and their brand of hate; and 3. The relationship between online activity and traditional forms and methods of communication.
\end{abstract}

\section{Introduction}

In the late 1990 s and early 2000 s there was much discussion of both the democratizing and anti-democratic implications of the internet, in the absence of clear controls or regulations and boundaries. In relation to the former thesis were progressive social movements, and in the latter, the far-right using the internet to spread their racist hate, network and recruit both domestically and globally (Back, Keith and Solomos 1998, 73; Daniels 2009, 39-40; Neiwert 2017, 215-216).

Despite early fears and claims that the Americans were at the forefront of the far-right internet revolution (Back, Keith and Solomos 1998, 74; Daniels 2009, 5), they did not harness or exploit this new technology quickly, effectively or widely (Daniels 2009, 7). With the exception of Don Black's Stormfront. According to Peter Sills, some of the early media coverage of the neo-Nazi BBS bulletin board network was 'exaggerated' (Berlet 2008). Many were still using printing presses and uploading material onto the webpages or 'cut and paste brochures'. Where the internet was harnessed was in countries with greater hate speech regulation in Europe and Canada (Back, Keith and Solomos 1998, 77). In these contexts, material produced in America was reproduced on the internet, in much the same way American printed ephemera and recordings had previously been disseminated 
through the post to places where it was illegal. Since the late 2000s, there has been an increased use of the internet by the far-right, which has led to greater attention paid to it by the media, monitoring organizations and researchers, the latter of which looking at the far-right online in relation to everything from identity and community formation (Bowman-Grieve 2009; Perry and Scrivens 2016) to monitoring, detection and countering extremism (Scrivens, Davies and Frank 2017). This interest and attention have increased in the Trump era in response to the Alt-Right and proliferation of far-right and white identity and misogynistic movements and subcultures, as well as more general racism and misogyny, online.

Such work on online extremism also relates to work on wider everyday online racism (Daniels 2009; Sharma and Brooker 2016) and misogyny (Garcia-Favaro and Gill 2016; Lumsden and Morgan 2017), as well as their intersection (Noble 2018), which have been on the rise and normalized under Trump. Yet, online racist extremism and wider online racism are rarely explicitly connected in work on the former, in the same way that work on the far-right/right-wing extremism and terrorism is often separated from work on mainstream, institutional, structural and everyday racism (Mondon and Winter 2017 and 2018; Winter 2017 and 2018), with some exceptions such as work by Daniels (2009). This chapter will contribute to research on far-right extremism by focusing on online activity and adding a historical perspective to this. It will also contribute to contemporary research and analysis of online othering, particularly racism and misogyny, by connecting it to research and analysis of the far-right. It will focus not on othering itself, but the movements involved in its production, dissemination and weaponization of it, the processes and politics involved and end results. It will also examine where wider online othering and the far-right intersect most directly (within society and the research), in terms of radicalization or red pilling.

This chapter will examine the history of the American far-right's use of the internet with respect to: 1 . How this history developed in response to political changes and emerging technologies; 2. How it reflected and changed the status of such movements and their brand of hate; and 3. The relationship between online activity and traditional forms and methods of communication.

\section{A new era and a new technology}

The story of the modern far-right which introduced the movement to and eventually operationalized the internet, began in the post-civil rights era, the late 1970s and early 1980s. After a period defending legal, institutional white 
supremacy, often through harassment, intimidation and violence, the Klan was faced with not only the passing of the Civil Rights Act in 1964, but investigation by the FBI's counterintelligence programme COINTELPRO and government hearings into the Activities of the Ku Klux Klan in the United States, which declared the organization 'un-American' (Winter 2018).

These developments pushed the once mainstream Klan into the margins and political wilderness. In response, new strategies emerged in the 1970s and 1980s, including former Grand Wizard of the Klan David Duke's attempt to 'mainstream' and run for elected office, including for President. Perhaps the most significant strategic path was taken by more radical Klansmen, Patriots, neo-Nazis and Christian Identity adherents, such as Aryan Nations, in what has been termed the $5^{\text {th }}$ era. They rejected the mainstream, underwent paramilitarization and advocated armed insurgency and white separatism. Many retreated, going off-grid and online. Corresponding to their politics and conspiracy theories, they viewed the internet as free from government and Jewish control.

The $5^{\text {th }}$ era began when former Texas Klansman and Aryan Nations ambassador and strategist Louis Beam Jr. issued his call to arms in the Inter-Klan Newsletter \& Survival Alert: 'where ballots fail, bullets will prevail' (Ridgeway 1990, 87). It was also in this traditional printed publication, in the Spring 1984 issue, that Beam announced Aryan Nations Liberty Net, cited as the first white supremacist online system and bulletin board (Berlet 2008). In the article 'Computers and the American Patriot', Beam wrote: 'American know-how has provided the technology which will allow those who love this country to save it from an ill-deserved fate' (Berlet 2008). In a subsequent article titled 'Announcing Aryan Nations/Ku Klux Klan Computer Net', he announced a 'special electronic code access available only to Aryan Nations/Ku Klux Klan officers and selected individuals' (Berlet 2008). In August 1984, a flyer circulated in Canada announcing remote access to material banned under Canadian law through Aryan Liberty Net (Berlet 2008).

It has also been claimed that it was George P. Dietz who launched his Info. International Network or Liberty Bell Net before Beam, earlier in 1984 (Berlet 2008). Dietz claimed it was ' $[\mathrm{t}]$ he only computer bulletin board system and uncontrolled information medium in the United States of America dedicated to the dissemination of historical facts--not fiction!' (Berlet 2008). Dietz had been mailing printed neo-Nazi publications throughout the US and to Europe where much of it was banned, and the BBS system was seen as a way 
around postal security. The early text on Dietz's BBS, run on an Apple ][e., consisted of articles from his monthly Liberty Bell magazine, published in print form from 1973 (Berlet 2008).

The year after Beam and Dietz set their systems up, former Klansman Tom Metzger, who founded and led White Aryan Resistance (WAR), announced the W.A.R. Computer Terminal, which ran on a Commodore 64 with a 300 bps modem in War '85, his printed newspaper (Berlet 2008). According to Metzger: 'Already White Aryan comrades of the North have destroyed the free speech blackout to our Canadian comrades' (Berlet 2008). He also provided a forum for racist video games such as 'Drive by 2' and 'Border Patrol' and ran listserv@resist.cpm (Daniels 2009, 101-103), and established The Insurgent network, which followed the trend of devolving responsibility and authority to individual activists, much as Beam would with his Leaderless Resistance strategy (Winter 2011a). According to Metzger, the Insurgent was 'a NETWORK of highly motivated White Racists. Each person is an individual leader in his or her own right. THE INSURGENT promotes the Lone-Wolf tactical concept' (Daniels 2009, 103). Each Insurgent associate was expected to post a message online directed at 'any Aryan patriot in America' to arrange for local cable access channel broadcast of Metzger's new cable TV program The World as We See It, later named Race and Reason (Daniels 2009, 101). He also ran call-in telephone hot lines, including the WAR Hotline with recorded messages containing racist material (Berlet 2008). This was not a technological revolution but entrepreneurship and expansion of platforms and opportunities for recruitment and exposure that also included appearances on TV talk shows, most notably Geraldo.

The groups that dominated the era were Aryan Nations, led by Richard Butler and including Beam as a member, and National Alliance, led by William Pierce. Despite Beam's bulletin board, Aryan Nations disseminated its message primarily through its magazine Calling Our Nation, Aryan Nations Newsletter and prison newsletter The Way, as well as their annual Aryan World Congress (Winter 2011a). It was at the 1983 Congress that The Order was formed and began its two-year wave of terror, including the murder of Jewish talk radio host Alan Berg in 1984 (Winter 2011b). The National Alliance produced the printed National Vanguard and Pierce wrote the books The Turner Diaries and Hunter, the former of which inspired The Order and Oklahoma City bomber Timothy McVeigh in 1995. In the $5^{\text {th }}$ era, it was written material and physical meetings which played a more significant role. 


\section{The far-right gets a website}

The first far-right website was Stormfront, created by former Alabama Klansman Don Black in 1995. He set it up after learning IT in prison while serving time for plotting to overthrow a Caribbean island (Berlet 2008). The name Stormfront was chosen for its connotations of a political or military front, and reference to Nazi stormtroopers, the Sturmabteilung or SA, as well as an analogy to a destructive, but cleansing weather front according to the Southern Poverty Law Center (SPLC). The motto was 'White Pride Worldwide', articulating the notion of translocal or global whiteness noted by Back, Keith and Solomos (1998), Daniels (2009) and Perry and Scrivens (2016). According to Black '[o]ur mission is to provide information not available in the controlled news media ['Jews media'] and to build a community of White activists working for the survival of our people' (Perry and Scrivens 2016).

Other far-right groups and activists were also developing websites at this time, such as Ed Fields of the National States Rights Party (NSRP) who published Truth at Last and Thom Robb of the Klan who published The Torch, as well as owning kkk.com and kkk.biz. Yet, these were one-way transfers of information where text was uploaded and viewed like traditional printed ephemera, termed 'cut and paste brochures' (Daniels 2009, 97-99). Stormfront was a larger more interactive, participatory forum for white nationalists. Building on the bulletin boards for its discussion message board, Stormfront users could post, read and respond to opinions, articles, news and events, and engage with each other.

In their 2012 study of Stormfront, Caren, Jowers and Gaby noted that the white supremacist movement relies on the internet's elimination of spatial boundaries to 'draw in otherwise isolated movement participants', resulting in what McKenna and Bargh refer to as 'demarginalization' (King and Leonard 2014, 259), socially, politically and geographically, allowing for the creation of a virtual white supremacist community (De Koster and Houtman 2008; Bowman-Grieve 2009), as opposed to a traditional organization dependant on formal recruitment. In her analysis of the development and potential of Stormfront's online recruitment, Daniels differentiates between active (create content and community) and passive (read only) participants. Under active there are active creators, innovators, early adapters, active sustaining members, active supporting members and active oppositional members. Under passive: passive supportive lurkers, passive curiosity seeking lurkers and passive oppositional lurkers. (Daniels 2009, 48-52). In terms of geography, Stormfront featured in chatrooms in 
Australia, Belgium, Britain, Canada, France, Germany, Hungary, Italy, Netherlands, South Africa and Switzerland (Daniels 2009, 42).

In the mid-1990s, Milton Kleim Jr., who was affiliated with National Alliance, authored the 'National Socialism Primer' and created the Usenet newsgroup, rec.music.white-power, published On Tactics and Strategy for USENET' on the Aryan Crusader Library Web and Aryan Network. In it, he argued:

USENET offers enormous opportunity for the Aryan Resistance to disseminate our message to the unaware and the ignorant. It is the only relatively uncensored (so far) free-forum mass medium which we have available (Back, Keith and Solomos 1998, 78). ${ }^{1}$

Kleim's strategy also included a call for 'cyber guerrillas', an online version of lone wolves and Leaderless Resistance, to 'move out beyond our present domain, and take up positions on "mainstream" groups' (Back, Keith and Solomos 1998, 79). Kleim included a list of usergroups to do this though: alt.politics.nationalism.white, alt.politics.white-power, alt.revolution.counter, alt.skinheads and alt.revisionism. (Back, Keith and Solomos 1998, 78).

Internet use by the far-right increased substantially in the early 2000 s and the US came to dominate the scene. In 2003, the Council of Europe, noted that the majority of hate sites were American with 2,500 out of 4000 being US-based (Daniels 2009, 5). Increased far-right online activity and mobilization was partly due to advances in technology, increased use, the normalization of the internet, new actors on the scene and new strategies. The farright online community initiative expanded in 2002-2003 with Jamie Kelso joining Stormfront and the emergence of Web 2.0 technology (Daniels 2009, 105). Kelso attempted to increase its profile and ideological range, and with Black, asserted a relatively non-sectarian stance. They invited participants to post and recruited established writers from traditional publishing, including Sam Dickson of the Council of Conservative Citizens and Willis Carto of the Holocaust-denial journal, The Barnes Review (Southern Poverty Law Center NDb). Duke also started participating that year, joining Thom Robb and others (Daniels 2009, 105). Stormfront also developed a 'Ladies Forum' (Daniels 2009, 72). As Black told the Newhouse News Service: 'Anyone can work

\footnotetext{
${ }^{1}$ Available at: $\underline{\text { http://www.burks.de/tactic.html }}$
} 
to promote our ideas without being a member of any organization. I used to be annoyed by people who didn't join my organization, but I see the advantage now' (Southern Poverty Law Center NDb).

In 2001, USA Today called Stormfront 'the most visited white supremacist site on the net' (Southern Poverty Law Center NDb). At the same time, other groups were trying to utilize the internet. World Church of the Creator (WCOTC) (operating under different variations of the name), founded by Ben Klassen and later led by Matt Hale, who took over upon Klassen's death and had global aspirations and an interest in the potential of the internet, registering numerous domains such as rahowa.com and wcotc.com (Daniels 2009, 94-95). Hale established a website and a webpage for children, WTOTC Kids!, although later admitting that it was a publicity stunt to generate media attention (Anti-Defamation League 2013). They lost the website in 2002 in a copyright infringement lawsuit (Southern Poverty Law Center NDa). By 2003, Stormfront saw membership reach 11,000, and by 2008, membership was over 133,000 registered users, with more able to view postings, although only approximately 20,000 were known to be active posters (Southern Poverty Law Center NDb). The growth of Stormfront and the far-right internet followed the wider growth and popularization of the internet and events around which the far-right mobilized, including 9/11 and the elections of Barack Obama and Donald Trump.

\section{Between 9/11 and a black president}

The terrorist attacks on 9/11 saw a boom in both internet conspiracy theories, most notably Alex Jones' InfoWars, and, for a far-right in decline, an opportunity to get in on the action, most notably Aryan Nations. The organization had lost its dominant position following a SPLC lawsuit that resulted in them losing their compound, and leadership struggles. With founder Richard Butler in ill health at the time of 9/11, a breakaway faction Aryan Nations/Posse Comitatus led by former webmaster August Kreis attempted to grab the momentum by trying to establish an alliance with al-Qaeda. Kreis posted 'Why Islam Is Our Ally' and, in the lead-up to the invasion of Iraq, issued an online call for volunteers (Southern Poverty Law Center 2001). While this has been used to show that an alliance was possible or building, it came only from the far-right and nothing resulted from it (Winter 2014).

In 2008, Obama's election led to an increase in far-right activism, recruitment and online activity (AntiDefamation League 2009; Holthouse 2009; US Department of Homeland Security 2009). According to Don Black, 2,000 people joined Stormfront the day after the election, central to its growth during this period. David 
Duke referred to Obama as a 'visual aid' that helped attract interest and recruits, claiming that his website saw traffic by 'unique users' increase from 15,000 to 40,000 a day (Winter 2018). At the same time as all this online activity, in 2010, Stormfront introduced the more traditional forums of Stormfront Radio and annual Smoky Mountain Summit near Knoxville, Tennessee, similar to what WAR and Aryan Nations did in the 1980s. By its 20th anniversary in 2015, Stormfront claimed 300,000 members (Southern Poverty Law Center NDb). In light of increased attention and controversies, Stormfront introduced guidelines in which members were warned not to use profanity or 'racial epithets', and not to post violent threats or describe illegal activity. Emojis of beer steines replaced swastikas (Southern Poverty Law Center NDb).

In the past number of years, we have seen a significant growth in the role of the internet, particularly social media, in far-right politics, attributable to both new technologies and platforms and Trump, as well as the backlash that brought them together. Trump's racist, nativist, white nationalist rhetoric online and off simultaneously attracted the far-right, many of whom, including Duke, Black and Stormfront, endorsed him (Winter 2018), and allowed for the legitimization and normalization of some of their ideas (Mondon and Winter 2018). Key to this was the emergence of a social media savvy Alt-Right, who were able to spread their ideas more diffusely and penetrate the mainstream using social media, and new platforms, in ways that traditional exclusive far-right forums could not.

\section{Social media gateway}

In their 2008 report Online Terror + Hate: The First Decade, the Simon Wiesenthal Center (SWC) analysed the use of Web 2.0 technologies by the far-right, pioneered by Stormfront, noting that it allowed for faster, as well as wider, more global, uploading, dissemination, sharing and participatory engagement with ideas and material that could help them engage youth culture and recruit. This was backed up by research from the International Network Against Cyberhate (INACH) (King and Leonard 2014, 138). As Daniels (2009) and Simi and Futrell (2010) argue, Web 2.0 allows for the creation of a virtual community, but with the emergence and popularization of social media, its potential and reach extends beyond what Stormfront had developed. It allows for 'demarginalization', compensating for the lack of 'critical mass in their own locale' (Simi and Futrell 2010 , 97), but unlike traditional exclusive far-right sites, social media allows the far-right to access and attract a wider, non-affiliated, white (predominantly male) population. 
According to the SWC, the far-right has increased its use of and activity on social media, including Facebook, as well as Second Life, YouTube, forums and blogs. They report that in 2014-15, there was a spike from 1, 500 to 11,500 in social networks, websites, forums and blogs promoting anti-Semitism, homophobia, hate music, terrorism and wider violence. While previously, the growth area for the far-right 'white nationalists' and their online presence was traditional websites, in this period, it was almost entirely in social networking (King and Leonard 2014, 137-138). Between 2012 and 2016, according to a report by George Washington University's Program on Extremism, there was a 600 percent increase in followers of American white-nationalist movements on Twitter alone (Reitman 2018). The SPLC noted the emergence of Facebook groups representing known hate groups: Aryan Nations, European Americans United, American Renaissance and League of the South (King and Leonard 2014, 146). In his manifesto, Anders Breivik, who killed eight people in a bombing in Oslo and 69 people in a gun attack at a Workers' Youth League (AUF) camp on Utøya in Norway on 22 July 2011, wrote about the function and potential of Facebook:

I spent thousands of hours doing this over a duration of more than 6 months (from 2 Facebook accounts) and I, alone, managed to send the compendium to more than 8000 dedicated nationalists this way. If only 100 of these 8000 heed the call we will be able to send the compendium to 800000 nationalists. (King and Leonard 2014, 135-136)

The SPLC also noted the emergence of new social networking sites devoted to white supremacism and nationalism, more targeted than generic social media but more modern and youthful than Stormfront, such as Dylan Wheller's Folkscom.com, which was founded in 2005 and attracted 2000 members before closing the same year. The following year, Todd Findley founded the National Socialist Movement affiliated NewSaxon.org. There was also Nazi Space ('White Powered') and Aryan Space (King and Leonard 2014, 154157), which explained its rationale: 'The reason why we established Aryan Space is very simple, there are many social networks for Moslems, Blacks, Asians etc, but I was unable to find any for Aryans' (King and Leonard 2014, 156).

In addition to such technology contributing to a sense of a global white nationalist community, operating in general online spaces can invite crackdowns on the presence of the hate groups and hate speech, such as Facebook bans. This, as Daniel's points out, can aid the sense of community by reaffirming narratives of 
persecution or victimization that made people vulnerable to the far-right and fuels their politics and recruitment (Daniels 2009 105). The combination of the creation of a community of white - and male - victimization and the ability to bring into it a broad base is key to understanding the success of Trump (an avid Twitter user, who has retweeted the far-right on occasion) and the growth and mainstream penetration of the far-right, most notably the Alt-Right, and its ideas.

\section{The alt-right}

The Alt-Right is a phenomenon that has become familiar to many in the wake of Trump's campaign and election, having put the far-right in the mainstream public consciousness and mobilized the internet. The SPLC define it as 'a set of far-right ideologies, groups and individuals whose core belief is that "white identity" is under attack by multicultural forces using "political correctness" and "social justice" to undermine white people and "their" civilization' (Southern Poverty Law Center NDc). It is known for its use of social media, trolling, online memes such as \#whitegenocide and Pepe the Frog, the rejection of establishment conservatism, edginess, youth orientation, white identitarianism and white nationalism (Southern Poverty Law Center NDc).

The term 'Alt-Right', based on 'Alternative Right', was coined in 2008 by Richard Spencer, a Trump supporter who was an editor of The American Conservative and Taki's Magazine, executive director of Washington Summit Publishers, founder of Radix Journal and heads the white nationalist think tank National Policy Institute, to describe a new movement organized around white identity and western civilization. Spencer launched the movement in 2010 with the establishment of the 'Alternative Right' blog, where he worked to develop the movement's ideological tenets. Other high profile proponents include Greg Johnson of the publishing house Counter-Currents, Jared Taylor of the journal American Renaissance, and Matthew Heimbach of the neo-Nazi Traditionalist Youth Network (TYN) (Southern Poverty Law Center NDc).

Two websites and virtual communities are the preeminent propaganda machines for the Alt-Right according to the SPLC, The Daily Stormer and The Right Stuff (TRS) (Hatewatch 2018b). The Daily Stormer is a neo-Nazi and white supremacist site founded in 2013 and edited by Anglin, replacing his previous website Total Fascism, and hosted by goDaddy. It was named after the Nazi paper, Der Sturmer and is known for its memes and troll army (Hatewatch 2018a). Anglin also claimed, like WCOTC before him, to target children for indoctrination (Hatewatch 2018a). TRS is an online forum established by Mike 'Enoch' Peinovich. It started as a political blog 
in 2012 and has since transformed into one of the largest Alt-Right media platforms, hosting a message board called the 504um and dozens of podcasts (Hatewatch 2018b).

Alt-Right is a contested term for the ways it obscures its racist white nationalism, white supremacism and fascism, and makes it appear different from the traditional far-right. Yet, what is particularly significant about the Alt-Right is its ability to appear new and edgy, appeal to youth culture and the fact that one ideology or organizational form does not prevail. According to George Hawley in Making Sense of the Alt-Right, in contrast to previous far-right movements, the Alt-Right exists predominantly on social media (Hawley 2017). According to Anglin who argued: '[t]he movement (AR) is, at this point, entirely leaderless. The people involved in contributing to and/or consuming the content are on different Alt-Right sites and forums, many are on Twitter Reddit, 4chan etc.' (Hawley 2017, 70). The general population of the Alt-Right is composed of relatively anonymous youths who were exposed to the movement's ideas through online message boards and discussion threads like 4chan and 8chan's /pol/ and more mainstream internet platforms like Reddit, Facebook, Twitter and YouTube.

While it is known for its focus on fun, irony, irreverence and edginess, for those who would not associate with Klan or NSM (Hawley 2017, 25), the Daily Stormer is clearly fascist. Others attempt to bring these together, as demonstrated by the TRS's Fash the Nation (a reference to Face the Nation) and Daily Shoah (a reference to The Daily Show) podcasts. Other popular 'ironic' fascist references and memes include Adolf Hitler holding a PlayStation controller and anime characters such as 'Nazi Ponies', which was a Tumblr blog, a Twitter feed and series of YouTube videos (Reitman 2018).

According to Keegan Hankes of the SPLC, 'If you make racism or anti-Semitism funny, you can subvert the cultural taboo. Make people laugh at the Holocaust - you've opened a space in which history and fact become worthless, period' (Reitman 2018). This, and its anonymity, permits people to make unacceptable and even extreme comments, often moving from a discussion thread or Facebook group to more extreme forums and websites. This is a universe made up, as Mike Wendling argues, of racialists, intellectuals, channers, meninists, neo-nazis, conspiracy theorists and the violent fringe (Wendling 2018), as well as Men's Rights Activists (MRAs) (see also Lumsden, this volume). The less top down, active and uniform route into the Alt-Right and fascism is linked to red pilling or being red pilled, a term derived from The Matrix where taking a red pill allows 
one to see reality. In this context, it refers to the liberation of men from a life of delusion, particularly feminist delusion (Ging 2017), in line with the conspiracy culture of the far-right and internet, where the passive lurker is welcomed at various levels and the radicalization can occur as an individual becomes enculturated in an extreme, reactionary worldview (Ganesh 2018; Hawley 2017). It is about opening the 'Overton window', expanding the range of acceptable options and ideas on offer that can be seen as acceptable and be accepted (Wendling 2018, 91).

\section{The alt-lite, mainstream and red pilling}

According to research by the SPLC, the pathway to the Alt-Right is not singular. There are a range of platforms, individuals, organizations and movements, such as the so-called Alt-Lite, that populate the reactionary rightwing backlash which sees at its extreme end, the Alt-Right and fascism. In their study of pathways to the AltRight, the SPLC examine how people ended up at Daily Stormer and TRS, and what 'stepping stones' and 'inbetweeners' they engaged with and were influenced by (Hatewatch 2018b). In the SPLC and wider scholarly research, 4chan and 'chan culture' is identified as a significant factor in both the rise of the far-right and 'radicalization'. Nearly 23 percent of respondents to the SPLC study said that chan culture helped them land at TRS (Hatewatch 2018b). The main factor is the 'politically incorrect' 4chan /pol/ message board that is anonymous, traffics in humour and transgression, and operates away from mainstream scrutiny (Wendling 2018), which has nurtured the early Alt-Right and, especially, its misogyny and racism (Reitman 2018). In 'AllAmerican Nazis', Janet Reitman notes how 4chan's 'veil of obscurity' was used to incubate white nationalism. Discussion threads on white supremacist sites 'considered how /pol/ might be used to help young people become "racially aware" in an example of red pilling (Reitman 2018). Alongside /pol/, Reddit was another crucial space in the growth of the alt-right, particularly the subreddit r/The_Donald, that arose in support of Donald Trump's presidency (Hatewatch 2018b). According to the SPLC, YouTube's algorithm, which determines what will autoplay or be recommended after one video has finished, also plays a role in bringing viewers into the 'deeper depths of the alt-right' by presenting them escalating extreme content (Hatewatch 2018b)

In many cases, particular individuals and organizations are identified, as well as their online platforms, such as the more mainstream YouTube, The Rebel Media based in Canada and Breitbart, co-founded and run by former Trump advisor Steve Bannon. TRS 504um forum posters describe their radicalization as a 'gradual process,' with Alt-Lite personalities like Canadian Gavin McInnes, founder of the Proud Boys, Vice Media and Vice 
Magazine, as well as a contributor to Taki's Magazine and The Rebel Media, and introducing them to ideas about race, Islam, women and political correctness. Such social media figures (as well as lighter and more extreme ones) often present themselves and their ideas as a radical alternative and challenge to mainstream politically correct media and public opinion, and those who have accepted it, termed 'normies'. In this sense, they provide both rebellion and access to 'reality' for followers. One TRS 504um poster cited Stefan Molyneux, a Canadian 'Race Realist' anti-feminist YouTube vlogger and lecturer who has over 770,000 subscribers and 230 million views of his videos, as 'a great stepping stone between the Alt-Lite and the Alt-Right'. Other AltLite personalities include Lauren Southern, also Canadian and a former contributor to Rebel Media. Over 12 percent of TRS 504um users cited former Breitbart tech editor, anti-feminist, Islamophobic and 'free speech' activist Milo Yiannopoulos a factor in the escalation of their journey to the Alt-Right (Hatewatch 2018b).

Yiannopoulos was important as a central figure in the popularization of the Alt-Right, a popular representative of the Alt-Lite and a bridge between them and the mainstream. This is due to his role in Gamergate, which is alleged to have unleashed the Alt-Right, Alt-Lite and wider backlash, and where he made his name, and his position at Breitbart. In August 2014, a harassment campaign targeted several women in the video game industry, including developers Zoë Quinn and Brianna Wu, as well as feminist media critic Anita Sarkeesian who was, with others, critical of sexism and racism in games and gamer culture (Hawley 2017). \#gamergate hashtag users represented a backlash against such criticism and progressive politics in gamer culture. They also accused Quinn of an unethical, sexual, relationship with journalist Nathan Grayson in exchange for positive reviews. Gamergate supporters organized anonymously or pseudonymously on online platforms such as 4chan, Internet Relay Chat, Twitter and Reddit. After 4chan's founder Christopher Poole banned discussions of Gamergate from the site, the campaign's supporters migrated to the more extreme 8chan (Southern Poverty Law Center NDc). While racism is central to the Alt-Right, misogyny was always a significant factor in entry into the universe and being red pilled, which is itself an anti-feminist, MRA term (see also Lumsden, this volume). According to Debbie Ging (2017): 'Since the emergence of Web 2.0 and social media, a particularly toxic brand of antifeminism has become evident across a range of online networks and platforms'. She argues that the technological affordances of social media are especially well suited to the amplification of new articulations of aggrieved manhood. It can be expressed and fed through the wide network of blogs, forums and websites termed the 'manosphere'. Red pilling allows for the movement of the aggrieved and MRAs into the world of the more extreme Incel movement and white nationalism (Ging 2017). Yiannopoulos became famous supporting critics 
and white male game culture through his writing and media appearances (Hawley 2017). He was joined by Trump supporter Ricky Vaughn, a white nationalist who trolled in support of Trump during the election, and Michael Cernovich (O’Brian 2017). Yiannopoulos would later engage in other campaigns focusing on media and popular culture, most notably against the female Ghostbusters reboot, which included the racist trolling of Lesley Jones, leading to him and Vaughn being banned from Twitter (Hawley 2017, 162).

Following Gamergate, Yiannopoulos appeared in the mainstream media, was appointed editor at Breitbart and joined a growing group of controversial(ist) liberal, libertarian and conservative online commentators and public 'intellectuals' who represent themselves as exiles from and free speech rebels against mainstream politically correct or 'PC' culture for their opposition to anti-racism, feminism, transgender rights, identity-politics and the left. They include authors, Youtube vloggers and podcasters, such as Joe Rogan, Sargon of Akkad, Sam Harris, Ben Shapiro, Dave Rubin and Christian Hoff Sommers, as well as academics Bret and Eric Weinstein and Jordan Peterson, some of whom would later become known as part of the 'Intellectual Dark Web' (Weiss 2018). At the same time as occupying an increasingly mainstream position, Yiannopoulos wrote a primer on the AltRight, appeared with Richard Spencer, solicited advice from Daily Stormer system administrator Andrew 'Weev' Auernheimer and, with Breitbart, promoted, provided a platform for and mainstreamed the Alt-Right and their ideas (Bernstein 2017). ${ }^{2}$

\section{Online to offline and a crackdown}

What happens online can have an impact in the offline world. Trump's election, which was also promoted by Yiannopoulos, Bannon and Breitbart, is one case in point, violence is another. The Unite the Right rally in Charlottesville on 12 August 2017 was organized by Alt-Right webmaster Jason Kessler and attended by Richard Spencer, David Duke, the Klan, League of the South, Fraternal Order of Alt-Knights, Daily Stormer clubs, Traditionalist Worker Party, Vanguard America, Identity Evropa and others, in defence of the statue of Confederate General Robert E. Lee in Emancipation Park, and as an attempt to unite and show the strength of the far-right (Winter 2017). It exposed the movement's fascism and brought them from behind computer screens onto the streets, demonstrating that online hate can co-exist with old fashion tactics such as rallies and violence. The latter demonstrated by the murder of counter-protester Heather Heyer by James A. Fields of

\footnotetext{
${ }^{2}$ This period of mainstream popularity and influence for Yiannopoulos ended 2017 when he was revealed to have made pro-pedophilia comments, leading to Breitbart firing him and widespread rejection by media outlets, online platforms, fellow commentators and activists.
} 
Vanguard America and attack on DeAndre Harris by Jacob Goodwin, affiliated with the far-right ShieldWall Network, and others.

Since the election, there has been a rise in hate crimes, racist violence and vandalism in the US (Hatewatch 2016; Winter 2018), as well as more localized offline examples of far-right activity such as flyering and flyposting. Greg Johnson of the website Counter-Currents, spoke about the benefits of gaining media coverage through flyering and flyposting as a 'valuable form of asymmetrical cultural warfare' (Schwencke 2017). It also allows the far-right to target and stoke fear in communities directly and intimately in ways the internet does not allow for. Since September 2016, white supremacist groups have covered university campuses with fliers 118 times, according to the Anti-Defamation League (ADL) (Schwencke 2017). In addition to flyering and flyposting, universities have also seen public speeches by Alt-Right and Alt-Lite figures such as Spencer, McInnis, Yiannopoulos and others (Hawley 2017). Universities have become significant offline spaces for such far-right and more mainstream right-wing activism because they are seen as the front line in the fight for western civilization and free speech against the left, identity-politics, political correctness, anti-racism, feminism and LGBT rights, and so-called social justice warriors (SJWs).

In terms of online far-right hate being linked to violence, prior to Charlottesville registered Stormfront users have been disproportionately responsible for some of the most lethal hate crimes and mass killings (Southern Poverty Law Center 2014). Between 1999 and 2014 they murdered nearly 100 people, 77 of whom were massacred by Breivik (Southern Poverty Law Center 2014). Other examples of online related violence include the case of Dylann Roof. On 17 June, 2015, Roof launched an armed attacked on black worshippers at the Emanuel African Methodist Episcopal Church in Charleston, South Carolina. As he wrote in his manifesto, the Trayvon Martin killing "prompted me to type in the words "black on white crime" into Google, and I have never been the same since that day' (Hatewatch 2018c). His search led him to the website of the Council of Conservative Citizens which documented an alleged war against whites being waged by violent black people (Hatewatch 2018c). In another example, the neo-Nazi group Atomwaffen Division combined online activity on 4Chan, IronMarch.org, where they announced their formation, Daily Stormer, Discord, Twitter and Youtube, with offline tactics, such as flyposting on university campuses, and violence (Reitman 2018). This included combat training, hate attacks and terrorist plots (Reitman 2018). On Friday, May 19th, 2017, member Devon Arthurs shot his roommates and fellow members Andrew Oneschuk and Jeremy Himmelman in Florida. They 
met online and used 4chan. In another case, Brandon Russell, also a roommate of Arthurs and active blogger, was arrested and convicted for possessing explosives in 2017-18. The same year, member Samuel Woodward was arrested and charged for the killing of a gay Jewish student Blaze Bernstein in California (Reitman 2018). ${ }^{3}$

In response to the violence at the Unite the Right rally, a number of prominent tech companies decided, under pressure, to enforce existing 'acceptable use' policies and take action against groups that participated in the rally. As the SPLC (2018) stated, it took 'blood in the streets for tech companies to take action'. Yet, they argue that still 'some of the biggest tech companies keep hate group sites up and running', noting that Paypal, Bitcoin, Stripe, Network Solutions and others continue to provide services to designated hate groups (Southern Poverty Law Center 2018). ${ }^{4}$

Cases where there have been crackdowns include Twitter enforcing new policies to combat hate speech, abusive behaviour and particularly violence, leading to the suspension of accounts associated with white nationalism and banning groups 'that use or promote violence against civilians to further their causes' (Neidig 2017). GoDaddy pulled Richard Spencer's 'altright' website, and he was banned from Facebook (Broderick 2018). Despite this, Facebook parsed white reactionary ideologies, banning white supremacists, but allowing white nationalists and separatists (Kozlowska 2018), ignoring how these are related as racist ideologies, and that the latter two are used as part of the spin and softer appeal of the Alt-Right. The Daily Stormer found itself in digital exile after Anglin write an article mocking Heather Heyer, which led GoDaddy, Google, Namecheap and Cloudfare to cancel Daily Stormer's service (Lavin 2018). In response to the social media crackdown, there was a migration of farright groups and racist content to Google +, although a Google spokesperson asserted their dedication 'to keeping violent content and hate speech off our platforms' (Cuthbertson 2018). Fearing a crackdown, YouTube vloggers Southern, Molyneux and others moved to BitChute and cross-posted videos, while others moved to Gab (Daro and Lytvynenko 2018), set up in 2016 by Andrew Torba as a right-wing 'free speech' alternative to Twitter. Gab came under scrutiny and pressure though in October 2018 following the anti-Semitic attack at the

\footnotetext{
${ }^{3}$ The relationship between online hate and violence is not limited to the far-right. According to Müller and Schwarz, C. (2016), Trump's anti-Muslim tweets have been a reliable predictor of the level of attacks against Muslims.

${ }^{4}$ According to Ebner (2018), unregulated digital cryptocurrencies such as Bitcoin appeal to and have helped fund the far-right.
} 
Tree of Life Synagogue in Pittsburgh, Pennsylvania, which left 11 dead and others injured, by Robert Bowers, who had been active on the platform (BBC 2018).

However, the focus has primarily been on the role and responsibility of the private sector. While important, placing regulatory power in the hands of corporations is problematic. It depends on their fear of market and profit losses, leads to inconsistency, and promotes unaccountability. Government action, although problematic and potentially repressive, is not forthcoming. Trump not only failed to condemn the far-right following Charlottesville, but blamed 'many sides', referring to Antifa and other counter-protestors (Winter 2017). Furthermore, Homeland Security has targeted Antifa as a threat (Pasha-Robinson 2017). Anti-fascist activists have also been opposing the far-right online. Notable examples include the anarchist, anti-fascist online community and network It's Going Down, We Hunted the Mammoth, which 'tracks and mocks the white male rage underlying the rise of Trump and Trumpism' (We Hunted the Mammoth 2018), and Whack-a-Mole, a set of data mining programs that monitor 400,000 accounts of white nationalists on Facebook and other websites and feeds into a centralized database (Clark 2018). Anti-fascist and anti-racist activists also use doxxing, the tactic of releasing documents and data belonging to far-right activists online, to expose them, something the AltRight also engages in against targets and opponents (Hawley 2017). In addition to such online activism, there are also non-governmental organizations (NGOs) who monitor and combat the far-right online and off, such as the ADL, SPLC, SWC, Political Research Associates (PRA) and Hope Not Hate. It is an ongoing challenge in a context where the far-right and online hate adapt to opposition and obstacles.

\section{Conclusion}

This chapter examined the history, development and contemporary manifestations of the American far-right online in in relation to political and technological change, the changing status of the far-right and its brand of hate, and traditional forms and methods of communication. It sought to add a movement focused perspective to the analysis of wider online othering in this collection and both online and offline othering, particularly racism and sexism, more widely, including in mainstream politics and culture, and show the link between these. 


\section{References}

Anti-Defamation League (2009). Rage Grows in America: Anti-Government Conspiracies.

http://www.adl.org/special_reports/rage-grows-in-america/default.asp. Accessed 23 November 2009.

Anti-Defamation League (2013). Matt Hale.

https://www.adl.org/sites/default/files/documents/assets/pdf/combating-hate/Hale-Matt-EIA.pdf. Accessed 22 June 2018

Back, L., Keith, M. and Solomos, J. (1998). Racism on the internet: mapping neo-fascist subcultures in cyberspace. In: J. Kaplan and T. Bjorgo (Eds.), Nation and Race: The Developing Euro-American Racist Subculture. Boston: Northeastern University Press, pp. 73-101.

BBC. 2018, October 28. Pittsburgh shooting: What we know so far. BBC. https://www.bbc.co.uk/news/worldus-canada-46003665 . Accessed 20 December, 2018.

Berlet, C. (2008). When Hate Went Online. http://www.researchforprogress.us/topic/34691/when-hate-wentonline/. Accessed 14 April 2017.

Bernstein, J. (2017). Here's How Breitbart And Milo Smuggled White Nationalism into the Mainstream. Buzzfeed. 5 October 2017. https://www.buzzfeednews.com/article/josephbernstein/heres-how-breitbart-andmilo-smuggled-white-nationalism. Accessed 20 July 2018.

Bowman-Grieve, L. (2009). Exploring 'Stormfront': a virtual community of the radical right. Studies in Conflict \& Terrorism, $32(11), 989-1007$.

Broderick, R. (2018). Richard Spencer's website has been pulled offline By GoDaddy. Buzzfeed, 3 May 2018. https://www.buzzfeed.com/ryanhatesthis/richard-spencers-website-has-been-pulled-offline-bygodaddy?utm_term=.ftEk7w7MNA\#.hhenY2Yxq3. Accessed 4 May 2018. 
Clark, D.B. (2018). Meet Antifa's secret weapon against far-right extremists. Wired, 16 January 2018. https://www.wired.com/story/free-speech-issue-antifa-data-mining/. Accessed 20 June 2018.

Cuthbertson, A. (2018). Nazis and other extremists appear to be migrating to Google Plus after a crackdown from other social networks. The Independent, 15 June 2018. https://www.independent.co.uk/life-style/gadgetsand-tech/news/nazi-google-plus-facebook-twitter-white-supremacist-extremist-groups-a8401156.html. Accessed 20 June 2018.

Daniels, J. (2009). Cyber Racism: White Supremacy Online and the New Attack on Civil Rights. Lanham: Rowman and Littlefield.

Daro, I.N. and Lytvynenko, J. (2018). Right-wing YouTubers think it's only a matter of time before they get kicked off the site. Buzzfeed, 18 April 2018. https://www.buzzfeed.com/ishmaeldaro/right-wing-youtubealternative-platforms?utm_term=.tq5AqdqEVj\#.ngj6rxr97M. Accessed 20 June 2018.

De Koster, W. and Houtman, D. (2008). 'Stormfront is like a second home to me': On virtual community formation by right-wing extremists. Information, Communication \& Society, 11 (8), 1155-1176.

Ebner, J. (2018). The currency of the far-right: why neo-Nazis love bitcoin. The Guardian. 24 January 2018. https://www.theguardian.com/commentisfree/2018/jan/24/bitcoin-currency-far-right-neo-nazis-cryptocurrencies. Accessed 18 August 2018.

Ganesh, B. (2018). What the red pill means for radicals. Fair Observer, 7 June 2018.

https://www.fairobserver.com/world-news/incels-alt-right-manosphere-extremism-radicalism-news-51421/. Accessed 20 June 2018.

Garcia-Favaro, L. and Gill, R. (2016). 'Emasculation nation has arrived': Sexism rearticulated in online responses to Lose the Lads' Mags campaign. Feminist Media Studies, (16(3), 379-397. 
Ging, D. (2017). Alphas, betas, and incels: theorizing the masculinities of the manosphere. Men and Masculinities. https://doi.org/10.1177/1097184X17706401

Hatewatch (2016). Update: 1094 bias related incidents in the month following the election. Southern Poverty Law Center, 16 December 2016. https://www.splcenter.org/hatewatch/2016/12/16/update-1094-bias-relatedincidents-month-following-election. Accessed 1 April 2017.

Hatewatch (2018a). Andrew Anglin brags about 'indoctrinating' children into Nazi ideology. Southern Poverty Law Center, 18 January 2018. https://www.splcenter.org/hatewatch/2018/01/18/andrew-anglin-brags-aboutindoctrinating-children-nazi-ideology. Accessed 15 May 2018.

Hatewatch (2018b). McInnes, Molyneux, and 4chan: investigating pathways to the alt-right. Southern Poverty Law Center, 19 April 2018. https://www.splcenter.org/20180419/mcinnes-molyneux-and-4chan-investigatingpathways-alt-right. Accessed 22 April 2018.

Hatewatch (2018c). The biggest lie in the white supremacist propaganda playbook. Southern Poverty Law Center, 14 June 2018. https://www.splcenter.org/20180614/biggest-lie-white-supremacist-propagandaplaybook-unraveling-truth-about-'black-white-crime. Accessed 20 June 2018.

Hawley, G. (2017). Making Sense of the Alt-Right. New York: Columbia University Press.

King, R.C. and Leonard, D.J. (2014). Beyond Hate: White Power and Popular Culture. Farnham: Ashgate.

Holthouse, D. (2009). The year in hate: Number of hate groups tops 900. Intelligence Report. Spring. https://www.splcenter.org/intel/intelreport/article.jsp?aid=1027. Accessed 12 October 2009.

Kozlowska, H. (2018). Facebook forbids white supremacy, but allows white separatism and nationalism. Quartz, 26 May 2018. https://qz.com/1290044/facebook-forbids-white-supremacy-but-allows-white-separatism-andnationalism/. Accessed 30 May 2018. 
Lavin, T. (2018). The neo-Nazis of the Daily Stormer wander the digital wilderness. New Yorker, 7 January 2018. https://www.newyorker.com/tech/elements/the-neo-nazis-of-the-daily-stormer-wander-the-digitalwilderness. Accessed 22 April 2018.

Lumsden, K. and Morgan, H.M. (2017). Cyber-trolling as symbolic violence: deconstructing gendered abuse online. In: N. Lombard (Ed.), The Routledge Handbook of Gender and Violence. London: Routledge, pp. 121132.

Mondon, A. and Winter, A. (2017). Articulations of Islamophobia: From the Extreme to the Mainstream?.

Ethnic and Racial Studies Review, V. 40,\#13.

Mondon, A. and Winter, A. (2018). Understanding the Mainstreaming of the Far-Right. openDemocracy. 26 August 2018. https://www.opendemocracy.net/can-europe-make-it/aurelien-mondon-aaronwinter/understanding-mainstreaming-of-far-right. Accessed 26 August 2018.

Müller, K. and Schwarz, C. (2016). Making America Hate Again? Twitter and Hate Crime Under Trump. https://papers.ssrn.com/sol3/papers.cfm?abstract_id=3149103. Accessed 20 June 2018.

Neidig, H. (2017). Twitter launches hate speech crackdown. The Hill, 18 December 2017.

http:/thehill.com/policy/technology/365424-twitter-to-begin-enforcing-new-hate-speech-rules. Accessed 10 May 2018.

Neiwert, D. (2017). Alt-America: The Rise of the Radical Right in The Age of Trump. London: Verso.

Noble, S. U. (2018). Algorithms of Oppression: How Search Engines Reinforce Racism. New York: New York University Press.

O’Brian, L. (2017). Trump's most influential white nationalist troll. HuffPost US, 4 May 2017.

https://www.huffingtonpost.co.uk/entry/trump-white-nationalist-troll-rickyvaughn_us_5ac53167e4b09ef3b2432627. Accessed 15 June 2018. 
Pasha-Robinson, L. (2017). Antifa: US security agencies label group 'domestic terrorists. The Independent. 4 September 2017. https://www.independent.co.uk/news/world/americas/antifa-domestic-terrorists-us-securityagencies-homeland-security-fbi-a7927881.html. Accessed 20 April 2018.

Perry, B. and Scrivens, R. (2016). White pride worldwide: constructing global identities online. In: J. Schweppe and M. Walters (Eds.), The Globalisation of Hate: Internationalising Hate Crime. New York: Oxford University Press, pp, 65-78.

Reitman, J. (2018). 'All-American Nazis: how a senseless double murder in Florida exposed the rise of an organized fascist youth movement in the United States. Rolling Stone, 2 May 2018. https://www.rollingstone.com/politics/news/all-american-nazis-fascist-youth-united-states-w519651. Accessed 30 May 2018.

Ridgeway, J. (1990). Blood in the Face: The Ku Klux Klan, Aryan Nations, Nazi Skinheads, and The Rise of the New White Culture. New York: Thunder's Mouth Press.

Schwencke, K. (2017). A 2-for-1 for racists: post hateful fliers, and revel in the news coverage. ProPublica, 24 March 2017. https://www.propublica.org/article/a-2-for-1-for-racists-post-hateful-fliers-and-revel-in-the-newscoverage. Accessed 22 April 2018.

Sharma, S. and Brooker, P. (2016). \#notracist: Exploring Racism Denial Talk on Twitter. In:

Scrivens, R., Davies, G. and Frank, R. (2017). Searching for signs of extremism on the web: an introduction to sentiment-based identification of radical authors. Behavioural Sciences of Terrorism and Political Aggression, $10(1), 39-59$.

Simi, P. and Futrell, R. (2010). American Swastika: Inside the White Power Movement's Hidden Spaces of Hate. Lanham: Rowman and Littlefield. 
Southern Poverty Law Center (2001). 'Reaping the Whirlwind'. Intelligence Report.

http://www.splcenter.org/intelligenceproject/ip-4t3.html. Accessed December 102008.

Southern Poverty Law Center (2014) White homicide worldwide, 31 March 2014.

https://www.splcenter.org/20140331/white-homicide-worldwide. Accessed 22 April 2018.

Southern Poverty Law Center (2018). How tech supports hate. https://www.splcenter.org/hate-and-tech. Accessed 22 June 2018.

Southern Poverty Law Center (NDa). Matt Hale. https://www.splcenter.org/fighting-hate/extremistfiles/individual/matt-hale. Accessed 20 May 2018.

Southern Poverty Law Center (NDb). Stormfront. https://www.splcenter.org/fighting-hate/extremistfiles/group/stormfront. Accessed 10 April 2017.

Southern Poverty Law Center (NDc). Alt-Right. https://www.splcenter.org/fighting-hate/extremistfiles/ideology/alt-right. Accessed 10 April 2017.

US Department of Homeland Security (2009). Rightwing Extremism: Current Economic and Political Climate Fueling Resurgence in Radicalization and Recruitment. https://www.fas.org/irp/eprint/rightwing.pdf. Accessed 17 March 2017.

We Hunted the Mammoth. 2018. www.wehuntedthemammoth.com. Accessed 20 April, 2018.

Weiss, B. (2018). Meet the renegades of the intellectual dark web. New York Times, 8 May 2018. https://www.nytimes.com/2018/05/08/opinion/intellectual-dark-web.html. Accessed 10 June 2018.

Wendling, M. (2018). Alt-Right: From 4chan to the White Wendling House. London: Pluto Press. 
Winter, A. (2011a). Richard Butler. In: J.I. Ross (Ed.), Religion and Violence: An Encyclopedia of Faith and Conflict. Armonk: M.E. Sharpe, 122-126.

Winter, A. (2011b). The Order. In: J.I. Ross (Ed.), Religion and Violence: An Encyclopedia of Faith and Conflict. Armonk: M.E. Sharpe, 542-546.

Winter, A. (2014). My enemies must be friends: the American extreme right, conspiracy theory, Islam and the Middle East. In: M. Reinkowski and M. Butter (Eds.), Conspiracy Theories in the Middle East and the United States: A Comparative Approach. Berlin: de Gruyter, pp. 35-58.

Winter, A. (2017). Charlottesville, far-right rallies, racism and relating to power. Open Democracy. https://www.opendemocracy.net/aaron-winter/charlottesville-far-right-rallies-racism-and-relating-to-power. Accessed 10 October 2018.

Winter, A. (2018). The Klan is history: a historical perspective on the revival of the far-right in 'post-racial' America. In: J. Morrison, A. Silke, J. Windle and A. Winter (Eds.), Historical Perspectives on Organised Crime and Terrorism. Abingdon: Routledge, pp. 109-132. 